\title{
LA CORRUPCIÓN POLÍTICA EN JUAN DE MARIANA
}

\author{
DAVID GARCÍA-MARTÍN SOUSA*
}

Fecha de recepción: 24 de junio de 2013.

Fecha de aceptación: 5 de mayo de 2015.

La Giges era un pastor que servía al entonces rey de Lidia. Un día sobrevino una gran tormenta y un terremoto que rasgó la tierra y produjo un abismo en el lugar en el que Giges llevaba el ganado a pastorear. Asombrado al ver esto, descendió al abismo y halló, entre otras maravillas que narran los mitos, un caballo de bronce, hueco y con ventanillas, a través de las cuales divisó adentro un cadáver de tamaño más grande que el de un hombre, según parecía, y que no tenía nada excepto un anillo de oro en la mano. Giges le quitó el anillo y salió del abismo. Ahora bien, los pastores hacían su reunión habitual para dar al rey el informe mensual concerniente a la hacienda, cuando llegó Giges llevando el anillo. Tras sentarse entre los demás, casualmente volvió el engaste del anillo hacia el interior de su mano. Al suceder esto se tornó invisible para los que estaban sentados allí, quienes se pusieron a hablar en torno a él como si se hubiera ido. Giges se asombró, y luego, examinando el anillo, dio vuelta al engaste hacia fuera y tornó a hacerse visible. Al advertirlo, experimentó con el anillo para ver si tenía tal propiedad, y comprobó que así era: cuando giraba el engaste hacia adentro, su dueño se hacía invisible, y cuando lo giraba hacia fuera, se hacía visible. En cuanto se hubo cerciorado de ello, maquinó el modo de formar parte de los que fueron a la residencia del rey como informantes; y una vez allí sedujo a la reina, y con ayuda de ella, mató al rey y se apoderó del gobierno. Por consiguiente, si existiesen dos anillos de esa índole y se otorgara uno a un hombre justo y otro a otro injusto, según la opinión

* Doctor en Filosofía Política por la Universidad de Sevilla y Máster en la Escuela Austriaca de Economía por la Universidad Rey Juan Carlos. davidgarciamar@ hotmail.com 
común no habría nadie tan íntegro que perseverara firmemente en la justicia y soportara abstenerse de los bienes ajenos, sin tocarlos, cuando podría tanto apoderarse de lo que quisiera del mercado, como, entrar en las casas, acostarse con la mujer que prefiriera, y tanto matar a unos como librar de las cadenas a otros, según su voluntad, y hacer todo como si fuera igual a un dios entre los hombres.

(Platón. La República 359d-360a)

Platón es considerado por algunos ilustres filósofos ${ }^{1}$ como el padre ideológico de los totalitarismos contemporáneos. Sin entrar a valorar estas consideraciones, considero que la grandeza de Platón fue la de haber esbozado, a la vez que exponía su teoría políti$\mathrm{ca}$, los argumentos opuestos a sus propias proposiciones. Huelga decir que con el tiempo, la Academia con Platón al frente, desembocó en el probabilismo.

Platón trasmite en este mito la simple idea de que el poder corrompe. Así de buena y breve es la conclusión. Giges, un humilde pastor, trabajo que representa la quintaesencia del pueblo, encuentra un medio que le permite alcanzar cualquier fin que se proponga. Es el famoso Hobbit que Tolkien dibujó en su tierra media. Es la criatura más dócil, sencilla y simple que uno pudiera imaginarse pero, en contacto con el anillo de poder, es arrastrado por la vorágine de la corrupción. Platón deduce que si hubiera dos anillos iguales, seríamos indiscernibles en nuestra acción política, por lo que la idea de límite de mi acción visible define la justica de la injusticia. Así pues, la misma idea de poder, unida a la del deseo, es ilimitada por definición. Y cuando ese poder ilimitado se hace carne, no hay cuerpo que la resista. La corrupción hace el resto. Primero al portador del anillo pero, inmediatamente después, al resto del cuerpo político y de la sociedad. Pero, ¿qué es la corrupción?

1 Popper, (145: 1945). 


\section{I \\ DE LA IDEA DE CORRUPCIÓN}

La plataforma lógica desde la que vamos a analizar la idea de corrupción requiere su correspondiente taxonomía, clasificación y crítica. Descartaremos las posiciones idealistas o espiritualistas que consideran que las ideas brotan de una conciencia subjetiva o, mutatis mutandis, por inspiración mística. Partiremos de hechos «indubitables» y de los que cualquiera puede asentir. Así pues, seguiremos una metodología crítica respecto a las ideas que iremos desarrollando en el presente artículo. Para abordar la clasificación del concepto de corrupción seguiré la ofrecida por el profesor Gustavo Bueno ${ }^{2}$ en el que exige cuatro criterios ontológicos para la idea de corrupción.

1. El criterio de la corporeidad. Para que algo sea corruptible ha de poseer corporeidad pero este criterio no exige exclusividad. Así, por ejemplo, Aristóteles ${ }^{3}$ consideraba a los astros corpóreos pero incorruptibles.

2. Ha de estar integrado e insertos en otros cuerpos y que esa integración sea dinámica, no meramente mecánica o geométrica. Nos topamos, de hecho, con la idea de identidad y unidad.

3. La corrupción de ese cuerpo en movimiento supone una transformación pero nunca una aniquilación.

4. Esas unidades corpóreas, cuando analizamos el organismo político, no se mueven a través de una armonía preestablecida, como sostienen las ensoñaciones socialdemócratas, krausista o incluso marxistas cuando alcancen el paraíso comunista, sino con disritmias permanentes que permite la interacción de unos cuerpos con otros. ${ }^{4}$

Puede comprobarse desde estas coordenadas que el término corrupción no es unívoco sino equívoco, esto es, tiene sentidos muy

\footnotetext{
2 Bueno (2009).

3 Aristóteles, Metafísica. 1069a-1076a.

${ }^{4}$ Leibniz (11: 2001). La armonía preestablecida supone que Dios, desde la creación, insufló en las unidades elementales (mónadas) un movimiento teleológico o finalista. Así lo vio Leibniz con su teoría de las mónadas, las cuales son negadas por metafísicas e idealistas.
} 
heterogéneos que es preciso clasificar u ordenar. El concepto de corrupción suscita la idea de podredumbre, de algo que provoca una reacción organoléptica de repugnancia y asco. Este sentido primario se expande, como concepto análogo de atribución, hacia el resto del campo semántico, volviéndose cada vez más confuso, perdiendo las líneas de visión de conjunto.

Lo más llamativo del concepto de corrupción aplicado a la política es que no abarca la totalidad del campo semántico cuando las actuaciones que el gobernante ejerce corrompen la república. A modo de ejemplo, se habla de corrupción cuando aparece una contabilidad negra de un partido político pero no se hace lo propio si el ejecutivo de ese mismo partido cierra un ejercicio presupuestario con déficit. ¿Existe acaso algo más corruptor de una sociedad que el déficit o la inflación o la devaluación de la moneda? ¿No corrompería más la sociedad el despilfarro que supondría la unión de todas las capitales de provincia con líneas de ferroviarias AVE que la mordida de un guardia civil de tráfico? Ya inmersos en la retórica política, ¿por qué no se habla de corrupción política cuando un parlamento regional proclama de manera unilateral la secesión?

Rodrigo Sánchez de Arévalo ${ }^{5}$ extiende el campo de la corrupción a la sociedad política entera:

Las pequeñas discordias entre los ciudadanos y súbditos crecen y aumentan de que viene corrupción en la ciudad», citando como de costumbre a Aristóteles, sostiene que «muchas veces acontece que tales discordias por las grandes adherencias de los discordantes, corrompen o al menos trasmudan las pollecías y regimientos.

Nuestros legisladores no consideran que entran en la idea de corrupción ni la traición, ni a sedición o rebelión, actos que otrora eran considerados como las más altas cotas de estupro. Llama la atención que se ha reducido la aplicación del concepto de corrupción a personas individuales, nunca a grupos por aquello de que las sociedades nunca pueden delinquir.

5 Suma de la Política (1454). 


\section{II EL ESTADO DE DERECHO}

Roberto Von Mohl, creador de la idea de Estado de derecho, estableció la distinción ontológica entre el Gobierno y la Asamblea Representativa. Los ministros representan antes la voluntad del Príncipe que la de alguna fracción parlamentaria. La cohesión o unidad del Estado quedaba garantizado por el Príncipe. Así, cualquier atisbo de corrupción quedaba circunscrito al ámbito de las conductas individuales que no afectaban, de ningún modo, a la estructura del Estado. Mientras que las personas de carne y hueso son las únicas susceptibles de sucumbir a la corrupción debido a los pecados capitales, soberbia, avaricia y lujuria, las instituciones disfrutan de un hado de incorruptibilidad por una especie de gracia santificante.

La creencia de que las sociedades-familia, grupo, banda, nación, empresa o país-no delinque, tuvo un respaldo definitivo durante el siglo XX con el juicio de Núremberg, cuyo propósito fue exculpar a Alemania de las atrocidades cometidas durante el imperio nazi. La culpa de los crímenes nazis se debió a un elenco de ciudadanos concretos, nunca al estado agente.

\section{III EL AGUSTINISMO POLÍTICO}

Otra aplicación del concepto de corrupción, cuya transcendencia en la Historia de las Ideas Políticas es importantísima, fue el agustinismo político. Su influencia sobre el marxismo, así como en los distintos nacionalismos y socialismos que tiñen el actual panorama político, es fundamental. Estas mitologías son, en palabras de Ettien Gilson, metamorfosis de la Ciudad de Dios. La obra de San Agustín ha inspirado gran parte de la metafísica política de occidente gracias a las diversas interpretaciones que la Iglesia Católica, el protestantismo y el socialismo han destilado de sus escritos. La secularización agustiniana, primero de la mano de Lutero, y posteriormente de los revolucionarios franceses, sirvió en bandeja al socialismo su corpus teórico. 
Para mostrar al lector esta influencia, haremos una brevísima exposición de la metafísica cristiana de corte agustiniano. In illo tempore, en un tiempo anterior a la historia humana, tuvo lugar la rebelión de los ángeles ante Dios. Esta narración mitológica posee una alegoría psicológica pragmática de las motivaciones que impulsan en general la conducta de los hombres en la Ciudad de Dios. Esta rebelión obedece a un concepto político interpretado en términos de soberbia:

Y cuando indagamos la causa de la miseria de los ángeles malos con razón se nos ofrece que es porque, volviendo las espaldas a Dios, se miraron a sí mismos, que no son sumos u omnipotentes; y a este vicio ¿cómo lo designaríamos sino con el nombre de soberbia? Porque la soberbia es el origen de todo pecado.

(ECLESIASTÉs 10,15)

En esencia, San Agustín desconfía del hombre, individualmente considerado, dejando el camino expedito para que, siglos después, un fraile de su congregación recogiese el testigo de la desconfianza ante el hombre para sumir a la cristiandad en siglos de guerras. Hablamos de Lutero.

Lutero, como buen agustino, partirá de esta misma antropología pesimista de la naturaleza humana, la cual muestra una tendencia a la corrupción individual de la carne:

Nosotros, los alemanes, pecamos y somos esclavos del pecado, vivimos en los placeres carnales y nos arrojamos a la libertad con el corazón alegre hasta las orejas. Queremos obrar a nuestra manera, servir los intereses del diablo y ser libres de hacer únicamente lo que nos place... Estamos muy contentos de habernos desembarazado del Papa, de los oficiales y de las otras leyes, pero de saber cómo debe servirse a Cristo y librarse de los pecados nadie se preocupa. ${ }^{6}$

Lutero concibió la política como un conflicto permanente, sin posibilidad de tregua o solución pactada. En cualquier caso, este

${ }^{6}$ Lutero XLVIII, p. 389. 
cuadro mitológico de pugna enturbia y desequilibra la paz y la armonía que reinaba en la primera sociedad jerárquica espiritual, constituida por las personas de la Santísima Trinidad y los coros angélicos que contemplaban en paz y libertad perpetuas. El pecado de la soberbia se reduce a la singularidad específica. Este pecado de los ángeles fue trasmitido al Género Humano, por Lucifer cuando tentó a Adán y Eva, que vivían en un paraíso gozando de la abundancia y falta de escasez. El pecado original, fruto igualmente de la soberbia, produce una alienación (término utilizado por San Agustín, que pasará después por idealismo alemán hasta eclosionar en el marxismo) que les llevaría a volverse hacía sí mismos, en lugar de mantenerse cara a Dios. Comienza desde ese mismo momento la corrupción o caída de la Edad de Oro.

El marxismo consiste en una secularización de este relato mitológico, puesto que el fin que persigue consiste en retornar a ese estado embrionario de la historia, en el que ni la escasez ni el conflicto turbaban la paz:

La primera edad que se creó fue la del oro, la que cultivaba la lealtad y el bien, sin autoridad, por propia iniciativa, sin ley. No existía el castigo ni el miedo, ni se leían amenazas en tablas de bronce ni suplicante la gente temía el rostro de su juez, sino que sin autoridad vivían seguros (...) La primavera era eterna (...) y la tierra producía sin arar frutos, y el campo sin barbecho se blanqueaba de espigas preñadas. Ya corrían ríos de leche, ya ríos de néctar, y amarilla miel goteaba de verde encina. ${ }^{7}$

El mito de la edad dorada es el fundamento de la metafísica política que estructuró la idea del paraíso comunista prometido en su biblia sui generis. Este relato mitológico ha acompañado las cosmovisiones del ser humano desde Hesíodo, ${ }^{8}$ con el mito de las edades, hasta las últimas revoluciones sudamericanas y caribeñas en las que se propagaba la idea de pérdida de un paraíso al que el mesías de turno permitiría retornar. El principal problema de la economía, la escasez, fruto de la avaricia y soberbia

\footnotetext{
7 Ovidio. Las metamorfosis, 110.

8 Hesíodo. Los trabajos y los días, 110.
} 
humana que, leyes que regulan la propiedad privada mediante, han provocado un exilio al que el socialismo marxista promete poner fin. Marx, su profeta, en el elegido para señalar el camino de regreso al paraíso perdido. Ese Género Humano cantado en la Internacional encuentra el camino de retorno a la tierra prometida. Ese paraíso comunista derivó en el estado de bienestar propio de la social-democracia cuando la URSS prometió educación, sanidad y trabajo a todos los miembros de su sociedad: se acabó la escasez.

Desde las coordenadas marxistas, la persona que disfruta de más bienes y servicios no es debido a su acierto en la cooperación social, cuando produce bienes y servicios a la sociedad. La riqueza no es la consecuencia de una disciplina de su comportamiento que le coadyuva a adecuarse a los demás. Para el marxismo la riqueza es fruto de la rapiña y el robo al resto, originando las desigualdades sociales. Por lo tanto, es de justicia la redistribución de la riqueza.

Este mismo esquema metafísico es aplicado a los nacionalismos, compartiendo exactamente las mismas fases: desde una Unidad Primordial, se produce una caída o alienación ${ }^{9}$ en el que se pasa de la unidad a la multiplicidad, haciéndose necesario un retorno o vuelta a la unidad. ${ }^{10}$ En el origen de los tiempos hubo una Euskal Herria pura y prístina, en la que ningún tipo de escasez enturbiaba la serenidad de sus moradores, hasta que una invasión castellana provocó que el pueblo vasco sufriese una alienación. El profeta Sabino Arana fue el elegido para mostrar el camino de retorno a esa tierra prometida. Se reproduce el mismo esquema metafísico en el que se da por supuesto lo que precisamente se ha de demostrar: una Unidad Primigenia que sufre una alienación o pérdida de la unidad o caída a la que es necesario regresar.

Lo más llamativo de esta concepción antropológica del hombre fue la supervivencia en la tradición anglosajona preñada de ribetes protestantes. Un texto clave que resume esta cosmovisión

\footnotetext{
9 Los filósofos estoicos lo llamaban pro-odós o salida de sí.

10 Explicatio-complicatio, terminología propia del estoicismo clásico. Podría traducirse como expansión-contracción.
} 
contra-actualista del hombre la podemos hallar en la Ciudad de Dios, cuando San Agustín dice:

Por el pecado de Adán, no solo cayó el primer hombre, sino que la naturaleza humana quedó corrompida y mudada, de manera que padeciera en sus miembros (individuales y sociales) la desobediencia y repugnancia de la concupiscencia y quedase sujeta a la necesidad de morir. ${ }^{11}$

El hombre es malo por su naturaleza pecaminosa. Solo cabe ante esta posición abandonarse a la fe y proceder a un salto al abismo, despojando de todo valor a la acción humana, una acción que puede domeñar la fe. El Dios voluntarista de los protestantes, caprichoso y alejado completamente del hombre, cuya motivación por la que decide salvar a un determinado hombre están en un plano inaccesible para la razón humana, otorga al Príncipe la representación de la voluntad de Dios sobre la tierra, bajo la forma de Estado Absolutista. Y la soberanía reside allí en quien decide sobre el Estado de Excepción, esto es, la fuerza. ${ }^{12}$ La naturaleza humana necesita del Estado para que su naturaleza, caída y pecaminosa, deje de serlo y se eleve hacia Dios en un proceso que el idealismo alemán, de corte protestante denominó Aufghebung.

Es el pueblo de Dios un pueblo que engloba a la totalidad de sus individuos. Ya no hay distinción entre griegos y bárbaros, ni entre ricos ni pobres. ${ }^{13}$ Todos son el pueblo de Dios que, tras la encarnarse en el hombre, su naturaleza ha podido redimirse de su pecado original, pudiendo entrar en el Reino de los Cielos.

La corrupción es formulada en términos teológicos, mitológicos pero estructurados y con su despliegue teórico. Si es imposible eliminar la corrupción política desde la ciudad de Caín, será la otra ciudad, la de Abel, el refugio seguro para tal elevación. Esta ciudad de Abel es la Iglesia, secularizada en la democracia con la figura del Partido. Así cómo solo hay una Iglesia, la de Roma,

11 San Agustín, Libro XIII, III.

12 Teología política: «Es soberano quien decide el estado de excepción» TP, p. 23 Schmitt, Carl.

13 Gálatas 3: 28 : «No hay judíos ni griegos; no hay esclavos ni libres; no hay hombre ni mujer; porque todos sois uno en Cristo Jesús». 
solo hay un Partido, el comunista. El Príncipe-estado, y con él todo su aparato burocrático, no pueden equivocarse o corromperse porque cuentan con la gracia santificante, ${ }^{14}$ quedando así legitimado el Estado a través del Volksgeist o espíritu del pueblo que lo hace digno de elevarse para entrar en el reino de los cielos.

Puesto que el pueblo-estado está imbuido de gracia santificante, circunscribir la corrupción al ámbito del código penal y que la culpa recaiga sobre el individuo tiene unas consecuencias dañinas porque impide poder perseguir la corrupción amparada por la ley. La corrupción entendida como separación de partes del cuerpo político, si es ilegal, puede ser perseguida. La que realmente destruye la sociedad porque imposibilita que sea perseguida es aquella que es amparada por la ley, especialmente las que destruyen la cooperación social. Y de ese género tenemos demasiados ejemplos.

Esta asunción supuso una novedad respecto a la tradición filosófico-política ya que, desde la teorización de Platón y Aristóteles, las sociedades políticas son el receptáculo de la metáfora de la corrupción. No así los sujetos corpóreos. Estos simplemente delinquen o no.

IV

\section{LA SOCIALDEMOCRACIA COMO EJEMPLO DE CORRUPCIÓN POLÍTICA}

La socialdemocracia como ideología democrática fue inspirada por Luis Blanc durante el periodo revolucionario de 1848. El propio Karl Marx, con cierto aire irónico, consideró que era un tibio sincretismo entre las reivindicaciones proletarias y burguesas:

A las reivindicaciones sociales del proletariado se les limó la punta revolucionaria y se les dio un giro democrático; a las exigencias democráticas de la pequeña burguesía se las despojó de la forma meramente política y se afiló su punta socialista. Así nació la socialdemocracia. ${ }^{15}$

${ }^{14}$ San Pablo, Carta a los romanos 4: 4.

${ }^{15}$ Marx, Karl. El dieciocho de Brumario. 
Las ideas del revolucionario francés fueron rápidamente absorbidas por Fernando Lasalle, protagonista del congreso de Eisenach, en el que se fundó el Partido Socialista Obrero Alemán, así como en otro congreso, esta vez en la ciudad alemana de Gotha, dando el nombre al célebre manifiesto:

La clase obrera procura, en primer término su emancipación dentro del marco del Estado nacional. ${ }^{16}$

La eterna lucha de clases marxista impele a la revolución de la clase obrera para con el sistema de producción capitalista. En esta relación se gesta la sempiterna creencia de que el rico es rico porque roba al pobre, hecho que legitima la acción-reacción de la clase obrera frente a la encarnación del poder tiránico capitalista. Así, la socialdemocracia contiene la simiente marxista en su esencia. Pero, a diferencia del marxismo beligerante, admite la posibilidad de hallar una solución «dialogada» o "pacífica» que ponga fin a la pugna de intereses, siempre y cuando ese supuesto diálogo concluya en la consecución de sus intereses.

Pero la experiencia nos ha mostrado qué entiende la socialdemocracia por solución dialogada al supuesto conflicto de intereses entre capitalistas y trabajadores. Y digo supuesta porque tal conflicto es una burda estratagema creada por Marx con oscuros y abyectos fines. En una economía capitalista no existen conflictos entre la capitalista y trabajadores, sino acuerdos voluntarios entre ambas partes. Los conflictos aparecen cuando surgen, por generación espontánea, terceros que dicen representar los intereses de los más desvalidos: el estado y su apéndice, los sindicatos. Así, la socialdemocracia nace ya con el gen defectuoso del marxismo. Mientras Europa se desangraba en estos «dimes y diretes», los EE.UU. comenzaban ya a despuntar y elevar el nivel de vida de los trabajadores, sin contar apenas con labor sindical.

La justicia social, usando la doctrina social de la Iglesia, ${ }^{17}$ sería resuelta por el Estado, como medio, pero dirigida hacia el fin que los socialdemócratas eligiesen cuando conquistasen el poder

16 Marx, Karl: Crítica del Programa de Gotha, 18.

17 Catholicam Christi Ecclesiam, 6 de enero de 1967. 
del estado. Así, llevarían a la humanidad hacia el paraíso perdido pero de un modo menos sanguinario y más aséptico que el marxista: los impuestos. Y siendo el estado la herramienta coactiva per se para imponer, se hacía indispensable la conquista del estado para llevar al proletariado a la edad dorada en la que los ríos eran ora de leche, ora de miel. Mientras que los socialdemócratas veían al estado como una herramienta de primer orden para llevar a cabo su programa político, los marxistas lo veían como el enemigo al que hay que batir inmisericordemente. Si bien discutían por los medios, el fin era el mismo: el paraíso de la edad dorada.

La corrupción, aplicado a la política, es propia de cualquier tipo de estado. No existe ningún sistema, per se, superior ontológica o formalmente a otro. Todos son susceptibles de corromperse. Este principio, del que los escolásticos eran sabedores, ha sido orillado por un nuevo fenómeno que ha irrumpido en el escenario de la filosofía política, a saber: el fundamentalismo democrático. ${ }^{18}$

Allí donde el marxismo no ha triunfado, la retaguardia de la socialdemocracia aspira a llevar al pueblo al paraíso perdido. Por esto, precisamente, los teóricos marxistas vieron que, tras el estrepitoso derrumbe de la URSS, solo la mimesis de la socialdemocracia podría mantener viva la llama de su profeta barbudo. Fukuyama y compañía se apresuraron a sentenciar, con solemnidad de catedrales, que la historia había llegado a su fin. Y este final venía de la mano de la democracia.

\section{$\mathrm{V}$ \\ LA DEMOCRACIA: SISTEMA DE CASTAS}

Tal como si fuera el Espíritu Absoluto de Hegel, la democracia apareció frente al derrumbe soviético como la única solución plausible al problema de las relaciones nacionales e internacionales. La teoría de la democracia ha sido proyectada a través de la propaganda política como el único sistema político capaz de

18 Concepto acuñado por Gustavo Bueno y que da título a una de sus obras más relevantes. 
controlar todas las variables, cuyos componentes formaban un sistema procesual cerrado capaz de expandirse. Este sistema es cerrado y sus componentes serían la Libertad, la Igualdad y la Fraternidad. Estas ideas-fuerza, paradigma de la Revolución Francesa, no surgieron ex nihilo de una conciencia subjetiva por parte de los revolucionarios jacobinos, sino que ya estaban pululando por las calles de las principales plazas europeas. Estas ideas no fueron más que la trasformación a la política de los axiomas de la mecánica que Newton había postulado en sus Principia: libertad - todo cuerpo persevera en su estado de reposo o uniformemente rectilíneo salvo que una fuerza externa le obligue a cambiar; igualdad —es el principio de la dinámica según el cual, la fuerza es igual a la masa por la aceleración; y el principio de fraternidad-o de acción recíproca, más conocido como acción-reacción.

El profesor Huerta de Soto explica con lucidez ${ }^{19}$ las dramáticas consecuencias de aplicar la metodología de la física a la economía. Mutatis mutandis, aplicar la mecánica newtoniana a la res pública ha supuesto la misma asfixia metodológica. Los seres humanos nos organizamos a través de lo que Hayek denominó orden espontáneo. Es lógicamente imposible ordenar a través de mandatos coactivos una sociedad, por muy buena voluntad que tengan los dirigentes. Y si tienen buena voluntad es peor que si no la tienen. Cuando un dirigente político democrático esgrime una buena voluntad, es conveniente recordar las palabras del filósofo más leído por el nazismo:

No hay nada en el mundo, ni tampoco fuera de él, que pueda ser tenido por bueno sin limitación alguna sino la buena voluntad. ${ }^{20}$

La buena voluntad es una excrecencia del protestantismo pietista más peligroso que uno puede encontrar y esa es la principal consecuencia del fundamentalismo democrático. Solo un desalmado o un egoísta insolidario podría oponerse a la buena voluntad que destilan las Organizaciones no gubernamentales, las políticas sociales de las autonomías o cualquiera de las ocurrencias

19 Huerta de Soto (2010: 3).

20 Kant 1996: 19. 
con las que nos deleitan los filántropos que abundan por doquier en las democracias. La buena voluntad legitima el constante y perpetua saqueo por parte de la casta política al ciudadano. Si añadimos a este pietismo amanerado el sistema procesual cerrado de la mecánica de Newton, nos hallamos ante una vulgar tiranía, tal como reflejaba el verbo krathos en griego clásico. Que ese krathos lo ostente una persona, unas cuantas o la mayoría, es una simple cuestión de grado. Incluso aceptando la mayor, es preferible ser coadyuvado por uno que por muchos.

\section{VI \\ JUAN DE MARIANA}

Juan de Mariana es una de las grandes figuras de la historia de la filosofía pero que, por motivos oscuros, carece de la fama que sus aportaciones merecen. Apartado de las programaciones del sistema público de enseñanza, tanto en institutos como en universidades, ha quedado incomprensiblemente para el estudio de eruditos Quizás fue la leyenda negra protestante, la nefanda Ilustración o la desidia propia del español, lo cierto es que sus aportaciones a la filosofía política y a la economía han caído en el olvido.

Nacido en Talavera de la Reina, su obra magna fue De rege et regis institucione (Sobre la dignidad real y la educación del rey) y destaca por su célebre defensa del tiranicidio. Fiel a la vetusta tradición platónica de hacer de los reyes, filósofos, concibió su obra como un intento por dotar de prudencia al rey para que no perdiese dignidad regia ni cayese en la tentación de la tiranía. Siguiendo la doctrina paulina, Dios entrega la regia potestad (soberanía) al pueblo como bien recogen las voces latinas, Vox populi, vox dei o Salus populi suprema lex, y este a su vez lo delega en el príncipe si y solo si cumple con sus obligaciones de respetar la voluntad de Dios. A diferencia del protestantismo, no se entrega la regia potestad directamente al príncipe. El mundo protestante vio la representación de otra guisa: el pueblo recibe de Dios la soberanía pero se le da sin derecho a retorno; es el Leviatán hobbesiano, legitimando el absolutismo estatal: 
El único modo de erigir un poder común que pueda defenderlos de la invasión de extraños y de las injurias entre ellos mismos (...) es el de conferir todo su poder y toda su fuerza individuales a un solo hombre o a una asamblea de hombres que pueda reducir las voluntades de los súbditos a una sola voluntad (...) Una vez hecho esto, una multitud así unida en una persona es lo que llamamos ESTADO, en latín CÍVITAS. De este modo se genera ese gran LEVIATÁN, o mejor dicho, ese dios mortal a quien debemos, bajo el Dios Inmortal, nuestra paz y seguridad. ${ }^{21}$

Hobbes desdeña la dialéctica que habían mantenido cierta armonía en la Edad Media y Renacimiento: la dialéctica de las dos ciudades agustinianas, por medio de la cual la Iglesia de Roma limita al príncipe y este, a su vez, trata de someter a su diócesis. La teocracia ya tomaba cuerpo en el mundo anglosajón.

Ambas ciudades tienen fines diferentes, lo cual les lleva una eterna pugna: la ciudad terrenal es el poder político, la ciudad de Caín que posee la fuerza bruta y se enfrenta a Abel, que es el poder religioso o la sociedad civil. ${ }^{22}$ En la ciudad de Dios sus moradores son libres de desarrollar sus fines últimos e iguales ante la ley de Dios; libres porque no existen obstáculos y porque pueden disponer de sus bienes sin que nadie esté legitimado para impedirlo; iguales ante la ley, no mediante. Sin embargo, el dios de Lutero y Calvino es caprichoso y voluntarista, cuya criaturas creadas no son análogas como en el tomismo, simpliciter diversa secundum quid eadem. Para el tomismo católico hay una analogía entre dios y la creación, mientras que para el protestante cada criatura es creada de la nada y sin ninguna relación, hecho que sume en la contingencia más absoluta al hombre y cuya única salida posible es el salto al abismo de la fe. Solo queda plegarse ante la voluntad de Dios encarnada por el poder terrenal de unos príncipes teocráticos.

Este es el contexto en el que se mueve Juan de Mariana, el de un Imperio Católico con una clara vocación universal en el que

21 Hobbes 1999: 157.

22 San Agustín fue el creador del concepto de «sociedad civil» como ente opuesto ontológicamente al poder político. 
se le advierte al rey de las consecuencias que podrían acarrearle si rebasa los límites: la muerte.

Dos amores, fundaron, pues, dos ciudades, a saber: el amor propio hasta el desprecio de Dios, la terrena, y el amor de Dios hasta el desprecio de sí propio, la celestial. La primera se gloría en sí misma, y la segunda, en Dios...En aquella, sus príncipes y las naciones avasalladas se ven bajo el yugo de la concupiscencia del dominio, y en esta sirven en mutua caridad, los gobernantes aconsejando y los súbditos obedeciendo». ${ }^{23}$

El padre Mariana reproduce la taxonomía aristotélica de las formas de gobierno. ${ }^{24}$ Existen tres formas de gobierno rectas o puras y la posibilidad de que esas mismas tres formas se transformen en impuras. Las formas rectas, siguiendo la lógica de proposiciones, son la monarquí, aristocracia y república; gobierno de uno, algunos o todos. Mientras que las formas impuras devienen en tiranía, oligarquía y democracia.

En el capítulo VI titulado Si es lícito matar al tirano dice que el tirano es odiado por Dios y por los hombres. Comienza con los ejemplos de tiranicidio de Enrique III de Francia. A continuación expone:

El pueblo, en donde tiene su origen la potestad regia, dicen, si así lo exigen las circunstancias, no solo tiene facultad para llamar a derecho al rey, sino también para despojarle de la corona si se niega a corregir sus faltas. El pueblo le ha transmitido su poder, pero se ha reservado otro mayor y así, para imponer tributos o para cambiar sus leyes fundamentales, es siempre indispensable su consentimiento. ${ }^{25}$

Mariana recoge parte de la tradición republicana al reproducir el concepto de patriotismo entendido como la tierra en la que están enterrados nuestros muertos y a la que le debemos la vida, la lengua, la moral y nuestro ser a través de las instituciones:

23 San Agustín, La Ciudad de Dios, XIV 28.

24 Aristóteles, La Política Pol., III, cap. VII, 1279a.

25 Mariana 1981: 77. 
¿Hemos de consentir que un tirano veje y atormente a su capricho nuestra patria, a la cual debemos más que a nuestros padres? (...) aunque hayamos de poner en riesgo la riqueza, la salud y la vida hemos de salvar la patria del peligro de la ruina. ${ }^{26}$

Tanto los teólogos como los filósofos sostienen que si un príncipe se apoderó de la república por la fuerza de las armas y sin que interviniera el consentimiento del pueblo, puede ser despojado por cualquiera del gobierno y de la vida.

La misión del rey es la de proteger las fronteras con los recursos que la Ciudad de Dios le pone a su alcance, pero el rey nunca puede saquear o imponer leyes dentro de la sociedad civil. Si cruza esa línea roja los sujetos operatorios o el hombre en tanto en cuanto empresario está legitimado por Dios para matar, no al rey porque ya ha perdido su condición, sino al tirano. Esa razón le dice que en economía no debe meter sus zarpas; que en política se someta a las Cortes castellanas; que en sociedad, deje al pueblo completa libertad para moverse en la búsqueda de su porvenir. Así pues Mariana nos pinta un rey bastante contemporáneo, por así decirlo, describiendo al tirano de la siguiente guisa:

Sustrae la propiedad de los particulares y la saquea, impelido por vicios tan impropios de un rey como la lujuria, la avaricia, la crueldad y el fraude ${ }^{27}$ (...) los tiranos intentan perjudicar y arruinar a todo el mundo, pero dirigen sus ataques en especial contra los hombres ricos y justos que viven en su reino, consideran el bien más sospechoso que el mal, y temen como a nada precisamente esas mismas virtudes de las que carecen... los tiranos expulsan del reino a los mejores con la excusa de que ha de rebajarse a quienquiera que destaque sobre el resto... dejan exhausto al pueblo para que no pueda reunirse, exigiendo casi a diario nuevos tributos, promoviendo disputas entre los ciudadanos y empalmando el fin de una guerra con el comienzo de otra. De situaciones así

26 Mariana 1982: 79.

27 Las categorías políticas han de estar subordinadas a la moral. Es una muestra de que el catolicismo responde al canon griego de que la moral debe tutelar y guiar los asuntos políticos. En esta idea se desmarca claramente de Maquiavelo y de la tradición protestante que sucumbe ante un positivismo moral: lo que tiene éxito es bueno perse. 
surgieron las pirámides de Egipto $^{28}$ (...) el tirano no puede menos de temer que aquellos a quienes esclaviza puedan intentar derrocarlo... por eso prohíbe que los ciudadanos se reúnan o formen asambleas o discutan en común los asuntos del reino, arrebatándoles con métodos propios de policía secreta la ocasión misma de hablar o escuchar con libertad, impidiendo incluso que puedan expresar sus quejas libremente...

Pero sin lugar a dudas este fragmento de Mariana demuestra cómo la monarquía absoluta fue un invento protestante y hasta qué punto la Ilustración supuso una vuelta a las cavernas:

No es posible ignorar su maldad cuando trastornan toda la comunidad, se apoderan de las riquezas de todos, menosprecian las leyes y la religión del pueblo y desafían con su arrogancia y su impiedad al propio cielo (...). En este caso hay que pensar en el medio de destronarlos. Debe empezarse por declarar públicamente que no se le reconoce como rey. Y como esta declaración provocará necesariamente una guerra (...) y si fuera necesario y no hubiera otro modo de salvar la patria, matar al príncipe como enemigo público, con la autoridad legítima del derecho de defensa. Pues esta facultad reside en cualquier particular que, sin preocuparse de su castigo, y despreciando su propia vida, quiera ayudar a la salvación de su patria. ${ }^{29}$

El rey no puede imponer impuestos sin la aprobación de los ciudadanos, ni crear monopolios estatales pero además, tampoco podrá reducir el contenido de metal noble que hay en las monedas y que los ciudadanos utilizan como dinero ya que ello provocará el encarecimiento de todos los productos:

Si baja el dinero del valor legal, suben todas las mercadurías sin remedio, a la misma proporción que abajaron la moneda, y todo se sale a una cuarta. ${ }^{30}$

${ }^{28}$ La actualidad de este texto de Mariana encumbra aún más si cabe su pensamiento.

${ }^{29}$ Mariana (1981: 80).

30 Mariana (1987: 46). 
Mariana, fiel a la división agustiniana, niega la potestad del rey sobre la propiedad de sus vasallos y como buen aristotélico, apoya el axioma de que la sociedad comienza con la propiedad privada (oikós) y evoluciona hacia una sociedad política (polis) formada por hombres libres e iguales. ${ }^{31}$ La libertad es definida por la propiedad privada de la casa oikós. Si el rey grava impuestos sin consentimiento de los hombres libres de su reino, automáticamente se habrá convertido en tirano, corrompiéndose su esencia regia y deviniendo de rey en tirano. Ya no tiene la regia potestad.

Mariana considera que es un despropósito que un rey altere el contenido de la moneda. Este hecho automáticamente le convertiría en un malvado ya que confundiría la común consideración que los hombres tienen de las cosas ya que valoran las mercancías por su calidad, la abundancia o escasez. La tremenda entrada de metales preciosos precedente de América impuso un constante vaivén monetario, subiendo los precios de todos los productos hasta niveles insoportables.

Para Mariana el valor de las cosas se encuentra en la estimación subjetiva de las cosas, siguiendo la doctrina de Diego de Covarrubias y Leyva, el cual postuló que:

El valor de una cosa no depende de su naturaleza objetiva sino de la estimación subjetiva de los hombres, incluso aunque tal estimación sea alocada, ya que en las Indias el trigo se valora más que en España porque allí los hombres lo estiman más, y ello a pesar de que la naturaleza del trigo es la misma en ambos lugares. ${ }^{32}$

El abandono de esta noción subjetivista de la economía y de la teoría del valor supuso que una serie de ingenieros sociales fuesen los encargados de dotar de valor objetivo a lo que de suyo es subjetivo.

El programa de política económica de nuestros escolásticos está a las antípodas de lo que hoy día se entiende por economía política. Desde las facultades de economía se destilan manuales en

31 Aristóteles, La Política I.

32 Diego de Covarrubias y Leyva (1604: 131). 
los que se enseña a determinar objetivamente el valor de los bienes y servicios. El panorama actual ensalza todavía más aún si cabe la labor de nuestros escolásticos españoles, los cuales vieron con claridad la naturaleza subjetiva de los precios, una naturaleza que ni Dios, con toda su omnisciencia y omnipotencia, puede saber cómo el libre arbitrio del hombre valorará la naturaleza de las cosas. Dios puede saber el futuro contingente o las infinitas posibilidades de mi acción, pero no cuál será exactamente esa elección valorativa. Así, verbigracia, el jesuita Juan de Lugo dijo pretium justum mathematicum soli licet Deo notum, es decir, el precio justo de las cosas solo a Dios le es lícito conocerlo. A los simples mortales nos queda el mercado.

El protestante confía en Dios y así lo plasma en su moneda. Dios, que habla directamente a la conciencia de los hombres «elegidos», les dice el valor de su moneda. Cuando los presidentes de los Bancos Centrales de los países occidentales suben o bajan los tipos de interés se creen ungidos por la gracia divina y juegan a ser dioses. Para un católico debería ser una monstruosidad e incluso una blasfemia ver cómo una persona cree estar ungido por una gracia especial para conocer lo que de suyo es incognoscible. $Y$ ese conocimiento privativo y exclusivo es fruto de la arrogancia intelectual que el idealismo protestante ha vertido sobre la economía. Para un protestante ungido por la gracia del Espíritu Santo la adscripción irracional de la conciencia subjetiva le permite creer estar en condiciones de aprehender un conocimiento revelado por Dios porque habla a las conciencias de los hombres elegidos para tal fin. Es la doctrina de la predestinación aplicada a la configuración de la adoración al estado. Por estas razones, entre otras muchas, el liberalismo solo pudo comenzar en un contexto católico. Jamás pudo haber sido concebido la existencia de un Banco Central o Reserva Federal en un contexto católico, pero la historia siempre la escriben los vencedores.

\section{REFERENCIAS BIBLIOGRÁFICAS}

ARIstóteles (2001): La política. Ed. Gredos. Bueno, G. (2010): El Fundamentalismo democrático. Ed. Temas de Hoy. 
Cicerón (2000): La República. Ed. Gredos.

Gilson, E. (1972): La filosofía en la Edad Media. Ed. Gredos.

Hesíodo (2000): Los trabajos y los días. Ed. Gredos.

Hobbes, Th. (1999): Leviatán. Ed. Alianza.

Huerta De Soto, J. (2010): The theory of Dynamic efficiency. Ed. Routledge.

KANT, E. (1996): Fundamentación de la metafísica de las costumbres. Ed. Santillana.

LUtero (1543): Von den Juden und ihren Lügen, Wittenberg; XLVIII, p. 389. Citamos según la traducción y división en capítulos propuesta por Elías Bernard, c. 11.

MARIANA, J. DE (1981): Sobre la dignidad real y la educación del rey. Ed.

Centro de Estudios Constitucionales.

MARX, K. (1997): Crítica del programa de Gotha. Ed. Santillana.

Ovidio (2000): Las metamorfosis. Ed. Gredos.

Platón (2005): La República, Ed. Gredos.

Popper, K. (1945): Sociedad abierta y sus enemigos. Ed. Paidós.

Rothbard, M. (2012 y 2006): Historia del Pensamiento económico.

Unión Editorial. Volumen I-II. Madrid. (2. 를.

SAn Agustín: Civitas dei. Ed. Gredos.

SÁNCHEZ de Arévalo, R. (1954): Suma de la política.

Schmitт, C. (2001): Teología Política I, compilada en «Carl Schmitt teólogo de la política». Héctor Orestes Aguilar, Fondo de Cultura Económica, México D.F. 
